\title{
Pluripotency-associated genes in human nasopharyngeal carcinoma CNE-2 cells are reactivated by a unique epigenetic sub-microenvironment
}

\author{
Jun-Xia Cao ${ }^{1,2^{*}}$, Yu-Xin Cui ${ }^{3}$, Zi-Jie Long ${ }^{4}$, Zhong-Min Dai ${ }^{5}$, Ji-Yan Lin ${ }^{6}$, Yi Liang ${ }^{1}$, Fei-Meng Zheng ${ }^{1}$, Yi-Xin Zeng ${ }^{1}$,
} Quentin Liu ${ }^{1,4^{*}}$

\begin{abstract}
Background: There is increasing evidence that cancers contain their own stem-like cells, and particular attention has been paid to one subset of cancer-stem cells termed side population (SP). Stem cells under normal physical conditions are tightly controlled by their microenvironment, however, the regulatory role of the microenvironment surrounding cancer stem cells is not well characterized yet. In this study we found that the phenotype of SP can be "generated" by macrophage-like cells under conditioned culture. Furthermore the gene regulation pathway involved in cellular reprogramming process was investigated.
\end{abstract}

Methods: The selection and identification of SP in 50 CNE-2 single cell clones were performed by flow cytometry. The transwell assay and immunofluorescence staining were used to measure migration and cancer stem cell characters of non-SP single clone cells cultured with conditioned medium respectively. The subtraction suppression hybridization (SSH) technique and northern blotting analysis was applied to explore the pluripotency-associated genes under a unique epigenetic sub-microenvironment.

Results: Among 50 clones, only one did not possess SP subpopulation while others did. The non-SP cells induced by macrophage-like cells showed more aggressive characters, which increased cell migration compared with the control cells and showed some fraction of SP phenotype. These cells expressed distinguished level of pluripotencyassociated genes such as ADP-ribosylation factor-like 6 interacting protein (ARMER), poly ( $\mathrm{rC}$ ) binding protein 1 (PCBP1) and pyruvate dehydrogenase E1- $\beta$ subunit (PDHB) when subjected to the environment.

Conclusion: To our knowledge, this is the first study to demonstrate that non-SP single-clone cells can be induced to generate a SP phenotype when they are cultured with conditioned medium of macrophage-like cells, which is associated with the reactivation of pluripotency-associated genes.

\section{Background}

The hypothesis of cancer stem cell (CSC) suggests that neoplastic clones are maintained exclusively by a small subpopulation of cells that give rise to phenotypically diverse cancer cells [1-3]. CSCs were first identified in 1990s in hematological malignancies, mainly acute myelogenous leukemia (AML) and also in other subtypes like AML M0, M1, M2, M4, and M5, chronic myeloid

\footnotetext{
* Correspondence: jun-xia.cao@jax.org; liuq9@mail.sysu.edu.cn

${ }^{1}$ State Key Laboratory of Oncology in South China, Cancer Center, Sun Yatsen University, 650 Dongfeng Road, Guangzhou 510060, PR China
}

leukemia (CML), acute lymphoblastic leukemia (ALL), and multiple myeloma $[4,5]$. This subset of cancer cells was also found in solid tumors in the breast, brain, lung, prostrate, testis, ovary, stomach, colon, skin, liver and pancreas [6-11]. Thus, there is overwhelming evidence that certain pathways which regulate or maintain the extensive proliferative and self-renewal potential of the tumor clone are present in CSC.

It is known that niches control stem cell function, thus it may seem counterintuitive that CSCs would be located within these regulatory microenvironments.

\section{() Biomed Central}


Since this question was first raised in 2005 [12], soon in 2007 evidence was shown that the vascular niches in brain tumors are abnormal and contribute directly to the generation of CSCs and tumor growth [13]. Therefore, CSCs might arise from normal stem cells that have acquired mutations that enable them to escape from niche control. Alternatively, deregulation of extrinsic factors within the niche might lead to uncontrolled proliferation of stem cells and tumorigenesis [14]. The fate of CSCs depends upon aberrant niche microenvironments to some extent, thus these niches might represent targets for the treatment of cancer. We paid particular attention to the source of CSCs and possible regulatory pathway in nasopharyngeal carcinoma (NPC) microenvironment herein.

NPC is a malignancy of the head and neck region that arises from the epithelial cells that cover the surface and line of the nasopharynx. This disease was initially reported in 1901, and characterized clinically in 1922 [15]. It is endemic in many geographical regions, including Southern China and Southeast Asia, where the observed incidence rates range from 15 to 50 per 100,000 persons. Previous studies have reported that squamous cell carcinoma (former WHO type 1) accounts for approximately $25 \%$ of all NPC; whereas undifferentiated carcinoma (former WHO type 3) accounts for $95 \%$ of all cases in high incidence areas [15-18]. The management of recurrent cervical lymph node metastases in NPC after radiation and chemotherapy is a radical surgery of the lymph nodes of the neck with postoperative brachytherapy. The salvage surgical procedure for persistent or recurrent neck disease shows a 5 -year control rate of $66 \%$ and a 5 -year actuarial survival of $38 \%$ [18]. Thus, the control of the differentiation and metastases may be the key to understanding this carcinoma. Our study combining the NPC CSCs with microenvironment aimed to address this key question.

Some markers and phenotype of CSCs were similar to that of normal neural stem cells. For example, they express CD133 and nestin in brain cancer, CD44 in breast cancer and CD34 in leukemia $[4,5,7,8]$. Recent evidences demonstrate that ABCG5 and USP22 may be used as cancer stem cell marker $[19,20]$. On the other hand, a character of stem cells termed side population (SP) can be identified due to the cellular exclusion of Hoechst 33342 dye. The SP cells have been isolated by flow cytometric analysis from various types of adult tumor tissue where they possess stem cell activity, including lung adenocarcinoma, gastrointestinal cancers, head and neck squamous cell carcinoma, ovarian cancer, thyroid cancer, and hepatocellular carcinoma [21-27]. Here, we performed our work on human NPC CNE-2 cells, of which SP phenotype revealed several stem cell properties [28], to investigate whether NPC CSCs are tightly regulated by the immediate microenvironment, to evaluate the differential gene expression profile of the CSCs with microenvironment, and to find more specific stem cell marker for NPC CSCs.

In this study, we tried to identify cancer non-SP cell clone from human NPC cancer cell line CNE-2. Such non-SP cell clone was isolated and cultured with macrophage-like cells. We found that conditioned culture could induce generation of SP cells by the non-SP cells derived from both NPC and neuroblastoma cell lines. Moreover, we evaluated the cell cycle and migration ability of condition cultured non-SP cells, which cells showed G1/S arrest and enhanced motility compared with control. We further identified the differential gene profile in condition cultured non-SP cells by the subtraction suppression hybridization (SSH).

\section{Methods}

\section{Cell lines and reagents}

Human acute monocytic leukemia cell line THP-1, human nasopharyngeal cancer cell line CNE-2 and human neuroblastoma cell line SK-N-CH were obtained from American Tissue Culture Collection (Rockville, MD, USA).

Antibodies including CD133 and CD133-PE were purchased from Miltenyi Biotech (Bergisch Gladbach, Germany). All the other reagents were purchased from Sigma (St Louis, MO, USA) unless otherwise noted.

\section{Single clone selection}

Cells were seeded in a 24-well plate with $1 \mathrm{cell} / \mathrm{ml}$ and single cell clones were isolated from wells with only a solitary colony. Selecting 50 single cell clones were subjected to expansion culture until sufficient amounts of cells were obtained. The 50 single cell clones were detected by the flow cytometric analysis of SP and nonSP distribution respectively. One CNE-2 single clone is named CNE-2-2 with little SP phenotype.

\section{Macrophage-conditioned medium}

THP- 1 cells at a density of $0.5 \times 10^{6} / \mathrm{ml}$ were cultured in RPMI 1640 (Invitrogen, San Diego, CA, USA) supplemented with 10\% FBS (Hyclone, Logan, UT, USA) and $20 \mathrm{ng} / \mathrm{ml}$ phorbol 12-myristate 13-acetate (PMA) for 48 $\mathrm{h}$ at $37^{\circ} \mathrm{C}$ in a humidified atmosphere of $5 \% \mathrm{CO}_{2}$ incubator. After nonadherent cells were discarded, remaining cells were washed twice in PBS and once in RPMI 1640 with 15 -min incubation at $37^{\circ} \mathrm{C}$. These PMA induced macrophage-like cells were cultivated for $24 \mathrm{~h}$ with fresh RPMI 1640 containing 10\% FBS (8 ml per $75-\mathrm{cm}^{3}$ flask). The supernatant after culture was subsequently filtered and used as the macrophage-conditioned medium. 


\section{Cell culture}

NPC Cells were cultured in a $25-\mathrm{cm}^{2}$ tissue culture flask $\left(1.2 \times 10^{4}\right.$ cells $\left./ \mathrm{cm}^{2}\right)$ in RPMI 1640 supplemented with $10 \% \mathrm{FBS}, 50 \mathrm{U} / \mathrm{ml}$ penicillin and $50 \mu \mathrm{g} / \mathrm{ml}$ streptomycin for $24 \mathrm{~h}$. Cells were washed with PBS and the conditioned medium produced by PMA-activated THP-1 cells was added. After indicated cultivation days, nonadherent cells were gently washed away with PBS and adherent cells were harvested with $0.05 \%$ trypsin-EDTA for test.

\section{Flow cytometry}

To identify the SP cells in the cancer cells, we selected the single clone cells as described above. The cells were removed from the culture dish with trypsin/EDTA (Invitrogen) and resuspended at 10 cells per ml RPMI 1640 supplemented with $2 \% \mathrm{FBS}, 50 \mathrm{U} / \mathrm{ml}$ penicillin and 50 $\mu \mathrm{g} / \mathrm{ml}$ streptomycin. Cells were preincubated in a $1.5-\mathrm{ml}$ Eppendorf tube for $90 \mathrm{~min}$ at $37^{\circ} \mathrm{C}$ with $2.5 \mu \mathrm{g} / \mathrm{ml}$ Hoechst 33342 dye (Invitrogen), either alone or in combination with $50 \mathrm{M}$ verapamil, an inhibitor of some verapamil-sensitive ABC transporters [29]. Finally, the cells were counterstained with $1 \mu \mathrm{g} / \mathrm{ml}$ propidium iodide to label dead cells. Cells were analyzed in a FACSVantage fluorescence-activated cell sorter (Becton Dickinson). Propidium iodide-positive dead cells $(<15 \%)$ were excluded from the analysis.

The non-SP Cells from the single clone detected by FACS were seeded into a 6 -well plate at $1 \times 10^{5}$ cells/ well and incubated with conditioned medium at $37^{\circ} \mathrm{C}$. After $24 \mathrm{~h}$ of incubation, cells were collected with trypsin/EDTA. SK-N-CH cells were incubated with CD133$\mathrm{PE}$ antibody for 10 minutes at $4^{\circ} \mathrm{C}$ before FACS analysis. CNE-2-2 single-cell suspension was fixed in ice-cold $70 \%$ ethanol at $-20^{\circ} \mathrm{C}$ for $16 \mathrm{~h}$, labeled with propidium iodide $(50 \mu \mathrm{g} / \mathrm{ml})$ for at least $15 \mathrm{~min}$ in dark and analyzed directly on a FACSCalibur flow cytometer (Becton Dickinson Immunocytometry Systems, San Jose, CA, USA).

\section{Immunofluorescence staining}

Cells grown on cover slips were washed in cold PBS and fixed in $2 \%$ paraformaldehyde-PBS for $20 \mathrm{~min}$ and permeabilized in $0.5 \%$ Triton X-100 in PBS for $10 \mathrm{~min}$ at $4^{\circ} \mathrm{C}$. The cells were incubated with $1 \%$ BSA for $30 \mathrm{~min}$ at room temperature (RT) to block nonspecific binding before the primary antibody reaction. Cells were incubated with the primary antibodies to CD133 for $1 \mathrm{~h}$ at RT, and then a specific FITC conjugated secondary antibody for $1 \mathrm{~h}$. Cells were counterstained with DAPI $(1 \mu \mathrm{g} / \mu \mathrm{l})$, and examined using a fluorescence microscope (Olympus BX51).

\section{Transwell migration assay}

CNE-2-2 cells were starved overnight in assay media (RPMI 1640 with $1 \%$ FBS). The top chamber of a 24well transwell plate (Corning Inc.) was pretreated with
1\% Matrigel $^{\mathrm{TM}}$ (BD Biosciences, San Jose, CA, USA) in PBS and incubated $1 \mathrm{~h}$ at RT. Cells $\left(10^{5} / \mathrm{ml}\right)$ were added to the top chambers of the plates. Media with or without activated macrophage-like cells was added to both chambers. After overnight incubation, top cells were removed and bottom cells were fixed and stained with DAPI $(5 \mu \mathrm{g} / \mathrm{ml})$ to visualize nuclei. The number of migrating cells in five fields was counted under fluorescence microscope, and the mean for each chamber was determined.

\section{Nucleic acid preparation}

All of the cells were snap-frozen in liquid nitrogen and stored at $-80^{\circ} \mathrm{C}$. The tested cells were lysed in Trizol Reagent (Invitrogen, CA, USA), and total RNA was isolated according to the manufacturer's instructions. mRNA of the conditioned culture non-SP single cell clone and non-conditioned culture cells was purified from total RNA using the Oligotex mRNA Spin-Column kit (Qiagen, Hilden, Germany).

\section{Suppression subtractive hybridization (SSH)}

SSH was performed between conditioned culture nonSP single cell clone and non-conditioned culture cells using the PCR-Select cDNA Subtraction Kit (Clontech, Palo Alto, CA) according to the manufacturer's recommendations. In the subtraction, conditioned culture non-SP single clone cells were used as a tester and nonconditioned culture single clone cells were used as a driver. Double-strand cDNA was synthesized from poly (A)+ RNA and blunted according to the kit manual. Two tester populations were created with different adaptors, but no adaptors with the driver.

After two cycles of hybridization, we carried out 28 cycles of primary PCR and 21 cycles of secondary PCR with DNA polymerase (Promega, Madison, WI, USA) on a GeneAmp 2400 thermal cycler (PE Biosystems, Foster City, CA, USA). To evaluate the efficiency of cDNA subtraction, we compared the expression of human $\beta$-actin (NP_001092) using the primers as denoted on Table 1 in subtracted and unsubtracted PCR products respectively. The subtracted fragments were then inserted into the T/A cloning vector $\mathrm{pCR} 2.1$ TOPO (Invitrogen, CA, USA).

\section{Differential Screening}

120 individual recombinant clones were picked and used as templates for PCR amplification using vector primers M13F and M13R. Each PCR product (about $1 \mu \mathrm{l}$ ) was transferred to a nylon membrane (Hybond-N, Amersham Pharamacia Biotech, Uppsala, Sweden). For denaturing purposes, the membrane was submerged for 2 - 3 min in turn on the three pieces of Whatman $3 \mathrm{MM}$ paper saturated with $1.5 \mathrm{M} \mathrm{NaCl}$ and $0.5 \mathrm{M} \mathrm{NaOH}, 1.5$ 
Table 1 Northern blot probe primers

\begin{tabular}{lll}
\hline \multicolumn{2}{l}{ Gene symbol } & Primer sequence \\
\hline ARMER & F-primer & CGGAGGGAGATAATCGCAGCACCAAC \\
& R-primer & GAAGCAGGTTGGGACTTGTTGTCCC \\
PCBP1 & F-primer & CGCCGGAATGACTCCAGCTCTCC \\
& R-primer & CAGAAAGGGTTATTGAGGGAACCTAC \\
PDHB & F-primer & CGGTGTCTGGCTTGGTGGGAGAC \\
& R-primer & GAGTTATAACCTGGTCAATGGCTTGC \\
FUBI & F-primer & TTCAGATTCTAGAGTATGTCCTC \\
& R-primer & ATAGAATGGGATGCTGTCTGGGAA \\
$\beta$-actin & F-primer & CGCGCTCGTCGTCGACAACGGC \\
& R-primer & CGTACATGGCTGGGGTGTGAAGGTC \\
\hline
\end{tabular}

$\mathrm{M} \mathrm{NaCl}$ and $0.5 \mathrm{M}$ Tris- $\mathrm{HCl}(\mathrm{pH} 8.0), 0.2 \mathrm{M}$ Tris- $\mathrm{HCl}$ $(\mathrm{pH} 7.5)$ and $2 \times$ SSC buffer, respectively. Subtracted and unsubtracted PCR products were used as probes labeling with digoxigenin-dUTP at $37^{\circ} \mathrm{C}$ overnight according to the DIG High Prime Labeling Kit protocol (Roche Molecular Biochemicals, Mannheim, Germany). The dot blot hybridization was performed overnight at $42^{\circ} \mathrm{C}$ using the DIG Easy Hyb system (Roche Molecular Biochemicals, Mannheim, Germany) following the manufacturer's instructions. The blots were washed at RT twice at low stringency $(2 \times$ SSC, $0.1 \%$ SDS $)$ for $5 \mathrm{~min}$ and then at $68^{\circ} \mathrm{C}$ twice at high stringency $(0.1 \times \mathrm{SSC}$, $0.1 \%$ SDS) for $15 \mathrm{~min}$. Hybridized probes were subsequently detected by alkaline phosphatase-conjugated anti-DIG antibody and the CSPD chemiluminescent detection system (Roche Molecular Biochemicals, Mannheim, Germany).

\section{Sequencing and Sequence analysis}

Nucleotide sequences were compared with the GenBank using the BLASTn programs from the National Center for Biotechnology Information http://www.ncbi.nlm.nih. gov/BLAST/ and the BLASTx for the protein. Protein patterns were then identified by searching the PROSITE database http://www.expasy.ch/tools/ and Pfam database http://pfam.sanger.ac.uk/.

The DNA was sequenced from both strands on an ABI PRISM 377 Genetic Analyzer (PE Biosystems, Foster City, CA, USA).

\section{Northern blotting analysis}

Digoxigenin-labelled DNA probes were applied for Northern blotting analysis. Oligonucleotide primers for the DNA probes were designed based on the known sequences (Table 1 ). The programs were as follows: $94^{\circ}$ $\mathrm{C}$ for $5 \mathrm{~min}$, followed by 35 cycles of $30 \mathrm{sec}$ at $94^{\circ} \mathrm{C}, 30$ sec at $56^{\circ} \mathrm{C}$, and $90 \mathrm{sec}$ at $72^{\circ} \mathrm{C}$, and a final polymerization step at $72^{\circ} \mathrm{C}$ for $10 \mathrm{~min}$, and then the PCR products were purified using QIAquick PCR Purification Kit
(Qiagen, Hilden, Germany). The fragments were labeled with digoxigenin-dUTP as above.

Each set of total RNA was extracted from conditioned culture non-SP single clone cells and non-conditioned culture single clone cells described above. Total RNA was quantified on a spectrophotometer at $260 \mathrm{~nm}$. Aliquots containing $10 \mu \mathrm{g}$ of total RNA corresponding to each tissue were mixed with glyoxal and DMSO and heated at $50^{\circ} \mathrm{C}$ for $30 \mathrm{~min}$ and then placed on ice over 1 min. The treated RNAs were then separated through a $1 \%$ agarose (Seakem) gel. The intensity of ethidium bromide-stained rRNA bands was examined visually to ensure that equal amounts of total RNA were loaded onto the gels. The RNA was then transferred to a nylon membrane (Hybond-N, Amersham Pharamacia Biotech, Uppsala, Sweden), and UV cross-linked. Hybridization was performed overnight at $50^{\circ} \mathrm{C}$, washed at RT twice at low stringency for $5 \mathrm{~min}$ and then at $55^{\circ} \mathrm{C}$ twice at high stringency for $15 \mathrm{~min}$ and were detected as above.

\section{Results}

\section{Identification of SP cells in the CNE-2 single clones}

To determine whether different percentages of SP cells were contained in CNE-2 cells, we screened the CNE-2 cells by single clone selection. We stained the single clone cells respectively with Hoechst 33342, which is actively extruded by verapamil-sensitive $A B C$ transporters. The SP cells from representative single clone CNE2 ranged from $0.1 \%$ to $73.7 \%$ as estimated by FACS analysis (Fig. 1A, B and 1C). In each case, by definition, the number of SP cells was decreased greatly by treatment with verapamil (Fig. 1 bottom panel). We could detect little SP cells in just a single clone cell (Fig. 1C, clone 2 ). Thus, most of the CNE-2 cancer cell clones contained a small or big component of SP cells. Our study is focus on whether microenvironment might have an effect on the percentage of SP cell in CNE-2, i.e, whether it play a role in the cancer stem cell pool, so the further experiments were mainly performed the human CNE-2 single clone (namely CNE-2-2) with little SP phenotype.

We cultured the CNE-2-2 clone with conditioned medium and carried out FACS analysis for the presence of SP. As shown in Fig. 1D, the CNE-2-2 cell clone contained $9.8 \%$ SP cells after cultured with macrophage-like cells, whereas the control CNE-2-2 cells only contained $0.1 \% \mathrm{SP}$. The data therefore suggested that macrophage might be responsible for maintaining the CNE-2 cancer stem cell pool.

\section{Validation SP alteration in neuroblastoma SK-N-CH cells}

To further confirm the above phenomena, we selected another cell line, the human neuroblastoma cell line SK$\mathrm{N}-\mathrm{CH}$ in which we could barely detect the presence of 


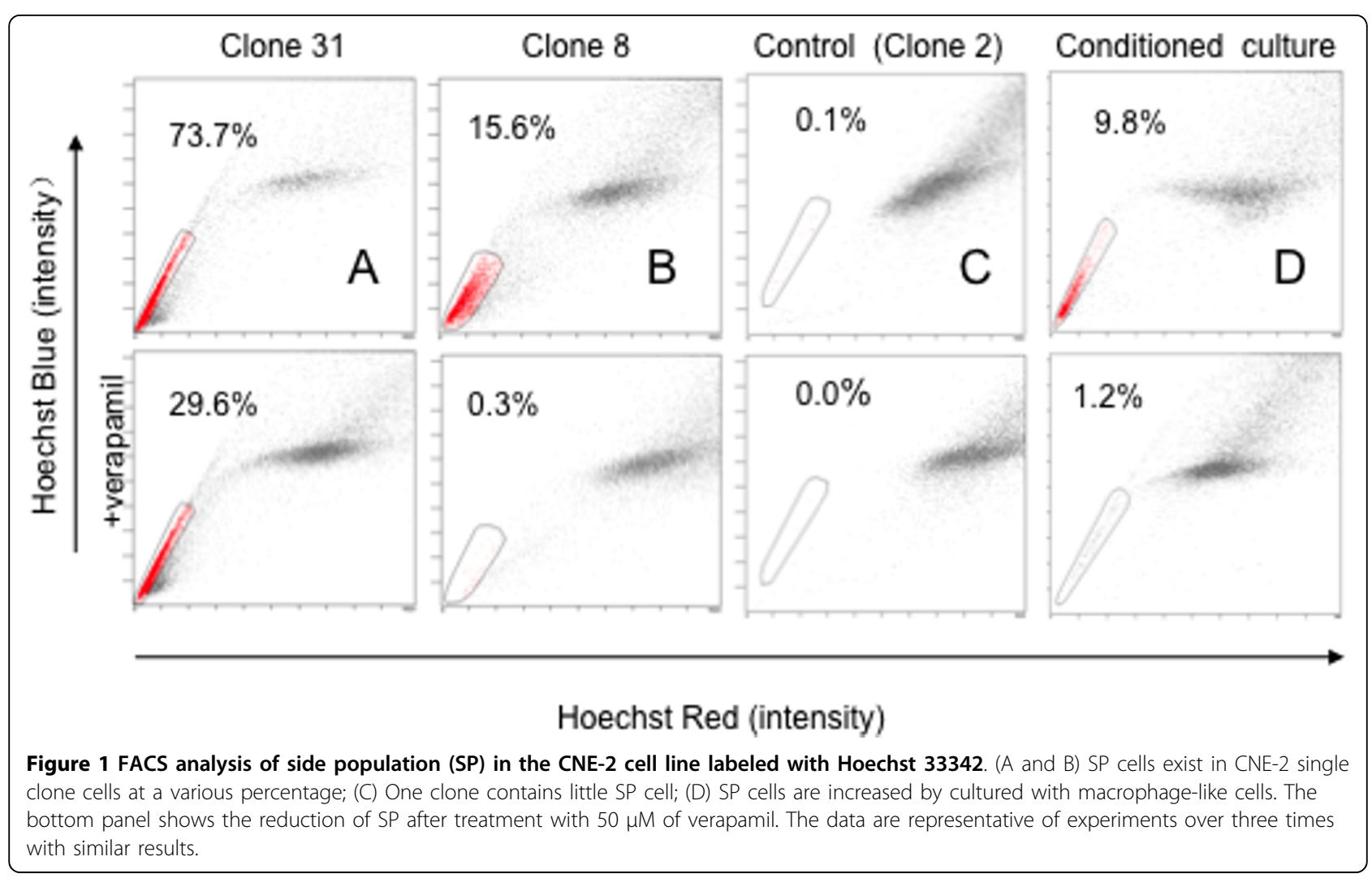

SP and the expression of CD133, one of the markers of neuroblastoma cancer stem cells. After cultured with activated macrophage medium, SK-N-CH cells were stained with CD133 antibody for FACS analyses. As shown in Fig. 2A, the condition cultured SK-N-CH cells contained $4.5 \%$ cancer stem cells, whereas the control SK-N-CH cells only contained $0.6 \%$.

Furthermore, we examined the expression of CD133 on SK-N-CH cells in response to the conditioned culture induced by macrophage-like cells with immunofluorescence. The fluorescence density of CD133 positive cells was evidently stronger than that in control (Fig. 2B). These results allowed us to conclude that human macrophages did play a role in maintaining cancer stem cell pool at least in several solid tumors.

\section{G1-S cell cycle and migration of CNE-2 single clone cell affected by conditioned culture}

Next, we analyzed cell cycle distribution in CNE-2-2 cells with conditioned medium. Cell cycle profiling of CNE-2-2 cells revealed that the conditioned culture induced reduction of the G1-S transition at 24 hours (Fig. 3A and 3B). By contrast, Control experiments showed no cell growth arrest features at 24 hours.

Following culture with activated macrophage-like cells, derived from human THP-1 cells, in a Transwell Boyden chamber system without cell-to-cell contact, CNE-2-2 cells resulted in a robust increase ( $>4$ folds) in cell motility after 18 hours, whereas in control the normal culture conditions did not enhance the migration ability of CNE-2-2 cells (Fig. 3C and 3D). Taken together, these results clearly indicated that the functional components in macrophage-like cells responsible for cancer stem cell were complicated.

\section{Differential gene expression profile of conditioned culture CNE-2 single clone cell}

The SP pool expansion, G1/S arrest and migration improvement in CNE-2-2 cells described above implied the cancer stem cell change in the cultured environment provided by macrophage-like cells. We further determined gene pathways involved during this process and studied the differential gene expression profiles between condition cultured and non-condition cultured CNE-2-2 cells by substractive suppression hybridization (SSH). About 120 clones were obtained from the SSH library enriched for the conditioned cultured CNE-2-2 cells transcripts. Following PCR using vector primers M13F and M13R and DNA dot-blot screening, 45 clones exhibiting expression differences were selected for DNA sequence analysis, which included 5 up-regulated (fold change $>2$ ) and 40 up-regulated (fold change $>1.2$ ) genes (Table 2). 


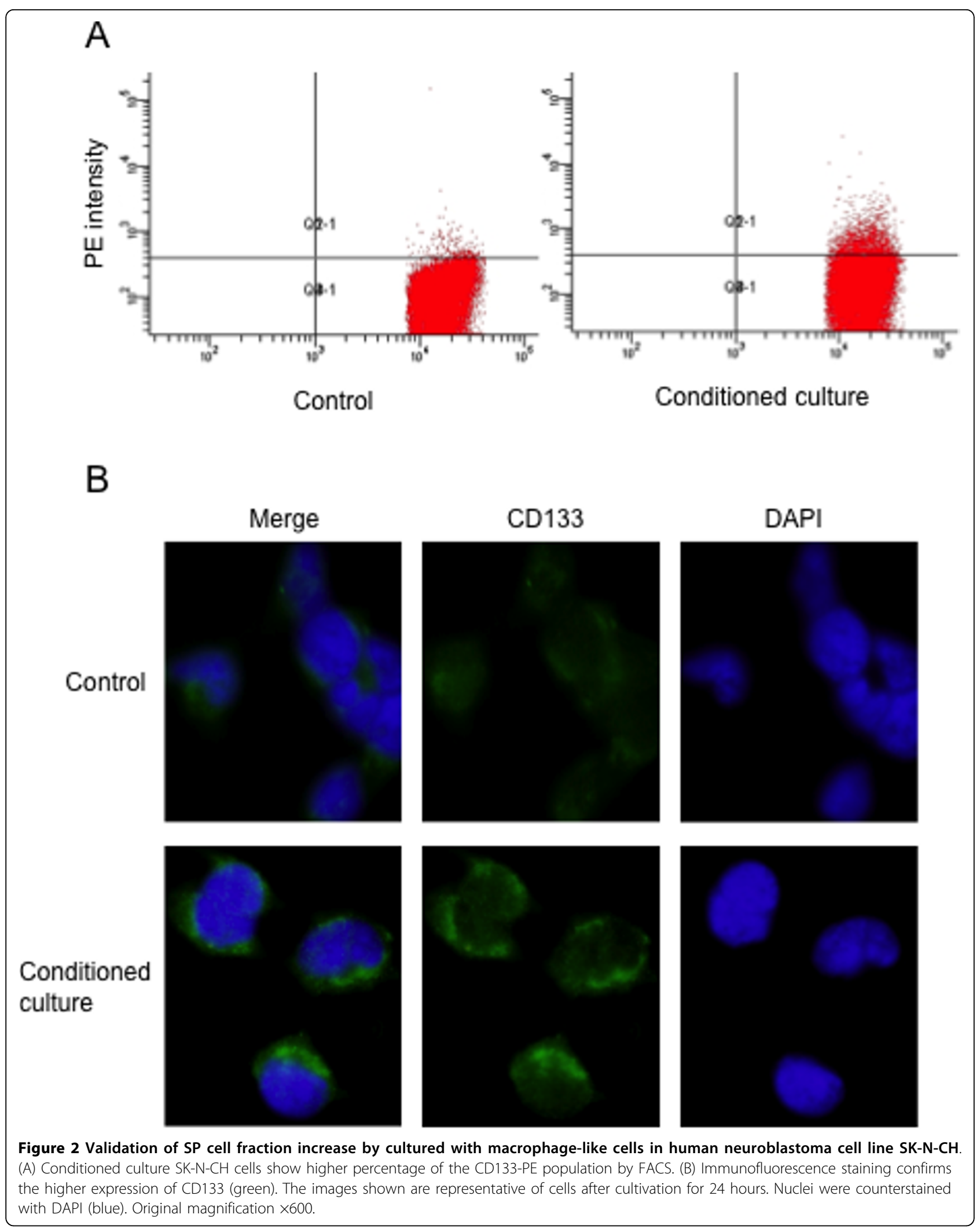




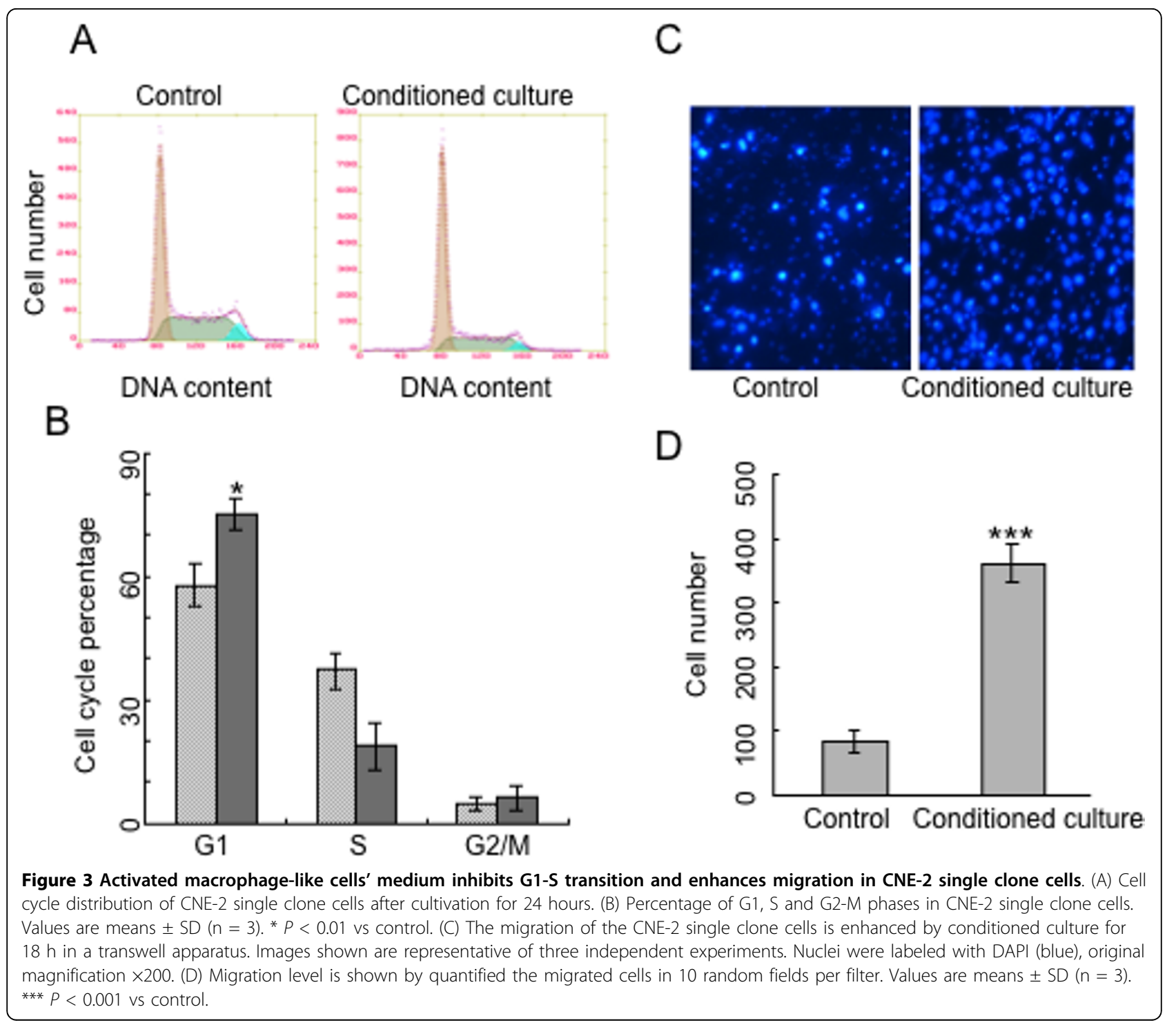

The SSH data was further validated by Northern blotting analysis. Results revealed that mRNAs of ADP-ribosylation factor-like 6 interacting protein (ARMER), poly (rC) binding protein 1 (PCBP1) and pyruvate dehydrogenase E1- $\beta$ subunit (PDHB) were only expressed in conditioned culture CNE-2-2 (Fig. 4A, B and 4C), and the level of ubiquitin-like protein fubi and ribosomal protein S30 precursor (FUBI) mRNA transcript was higher in conditioned cultured cells compared with control (Fig. 4D).

\section{Discussion}

In this study we have identified the non-SP cell clone in CNE-2 cells and found that conditioned culture non-SP cells were able to generate SP phenotype when microenvironment were present. Non-SP cells cultured with macrophage-like cells could not only produce heterologous descendent cells but also showed cell cycle arrest and higher cell motility. Furthermore we have determined the gene pathway involved during these processes by the SSH. To our knowledge, this is the first report to demonstrate the correlationship between non$\mathrm{SP}$ cells and microenvironment in a tumor.

The impetus to CSC-theory has been only recently proposed due to the advances in stem cell biology although the concept of CSCs is not new. We showed here for the first time that non-SP cancer cells cultured with macrophage-like cells were able to generate SP phenotype probably by asymmetric division or reprogramming. In addition, by using different cell line (SK-N-CH) and cancer stem cell marker CD133, we have observed the consistent phenomena. It has been reported that brain CSCs are maintained within vascular niches [13]. Here we provided evidences that CSCs depended upon aberrant 
Table 2 Categories of altered genes in CNE-2 single clone cells by macrophages-like cells during conditioned culture

\begin{tabular}{|c|c|c|}
\hline Accession No. & Gene description & Alteration \\
\hline NM_001012 & Ribosomes This gene encodes a ribosomal protein that is a component of the 405 subunit. & Up \\
\hline NM_002140.2 & heterogeneous nuclear ribonucleoproteins (hnRNPs) & Up \\
\hline NM_005174.2 & $\begin{array}{l}\text { Homo sapiens ATP synthase, } \mathrm{H}+\text { transporting, mitochondrial F1 complex, gamma polypeptide } 1 \text { (ATP5C1), nuclear } \\
\text { gene encoding mitochondrial protein, transcript variant 2, mRNA }\end{array}$ & Up \\
\hline NM_015937.3 & Homo sapiens phosphatidylinositol glycan anchor biosynthesis, class T (PIGT), mRNA & Up \\
\hline NM_018085.4 & Homo sapiens importin 9 (IPO9) & Up \\
\hline NM_000314.4 & Homo sapiens phosphatase and tensin homolog (PTEN) & Up \\
\hline NM_001033756.1 & Homo sapiens vascular endothelial growth factor A (VEGFA), transcript variant 7, mRNA & Up \\
\hline NM_003064.2 & Homo sapiens secretory leukocyte peptidase inhibitor (SLPI) & Up \\
\hline NM_002394.4 & $\begin{array}{l}\text { Homo sapiens solute carrier family } 3 \text { (activators of dibasic and neutral amino acid transport), member } 2 \text { (SLC3A2), } \\
\text { transcript variant } 3\end{array}$ & Up \\
\hline NM_005496.3 & Homo sapiens structural maintenance of chromosomes 4 (SMC4), transcript variant 1 & Up \\
\hline NM_006145.1 & Homo sapiens DnaJ (Hsp40) homolog, subfamily B, member 1 (DNAJB1) & Up \\
\hline NM_002306.2 & Homo sapiens lectin, galactoside-binding, soluble, 3 (LGALS3), transcript variant 1 & Up \\
\hline NM_020186.1 & Homo sapiens ACN9 homolog (S. cerevisiae) (ACN9) & Up \\
\hline NM_005347.2 & Homo sapiens heat shock 70 kDa protein 5 (glucose-regulated protein,78 kDa) (HSPA5) & Up \\
\hline NM_016639.1 & Homo sapiens tumor necrosis factor receptor superfamily, member 12A (TNFRSF12A) & Up \\
\hline NM_005348.3 & Homo sapiens heat shock protein $90 \mathrm{kDa}$ alpha (cytosolic), class A member 1 (HSP90AA1), transcript variant 2 & Up \\
\hline NM_194247.2 & Homo sapiens heterogeneous nuclear ribonucleoprotein A3 (HNRNPA3) & Up \\
\hline NM_004148.3 & Homo sapiens ninjurin 1 (NINJ1) & Up \\
\hline NM_002337.1 & Homo sapiens low density lipoprotein receptor-related protein associated protein 1 (LRPAP1) & Up \\
\hline NM_001003703.1 & $\begin{array}{l}\text { Homo sapiens ATP synthase, } \mathrm{H}+\text { transporting, mitochondrial F0 complex, subunit F6 (ATP5J), nuclear gene encoding } \\
\text { mitochondrial protein, transcript variant } 1\end{array}$ & Up \\
\hline NM_004048.2 & Homo sapiens beta-2-microglobulin (B2M) & Up \\
\hline NM_000146.3 & Homo sapiens ferritin, light polypeptide (FTL) & Up \\
\hline NM_001105079.1 & Homo sapiens fibrosin (FBRS), mRNA & Up \\
\hline NM_001002.3 & Homo sapiens ribosomal protein, large, P0 (RPLP0) transcript variant 1 & Up \\
\hline NM_015134.2 & Homo sapiens myosin phosphatase Rho interacting protein (MPRIP), transcript variant 1 & Up \\
\hline NM_004888.3 & Homo sapiens ATPase, $\mathrm{H}+$ transporting, lysosomal $13 \mathrm{kDa}$, V1 subunit G1 (ATP6V1G1) & Up \\
\hline NM_015161.1 & Homo sapiens ADP-ribosylation factor-like 6 interacting protein 1 (ARL6IP1) & Up \\
\hline NM_001001973.1 & $\begin{array}{l}\text { Homo sapiens ATP synthase, } \mathrm{H}+\text { transporting, mitochondrial F1 complex, gamma polypeptide } 1 \text { (ATP5C1), nuclear } \\
\text { gene encoding mitochondrial protein, transcript variant } 1\end{array}$ & Up \\
\hline NM_001997.3 & Homo sapiens Finkel-Biskis-Reilly murine sarcoma virus (FBR-MuSV) ubiquitously expressed (FAU) & Up \\
\hline NM_006196.2 & Homo sapiens poly(rC) binding protein 1 (PCBP1) & Up \\
\hline NM_000925.2 & Homo sapiens pyruvate dehydrogenase (lipoamide) beta (PDHB) & Up \\
\hline NR_003286.1 & Homo sapiens 185 ribosomal RNA (LOC100008588) & Up \\
\hline BAG64005.1 & unnamed protein product & Up \\
\hline NW_001838014.1 & Homo sapiens chromosome 10 genomic contig, alternate assembly & Up \\
\hline NT_007592.14 & Homo sapiens chromosome 6 genomic contig, reference assembly & Up \\
\hline NW_001839064.2 & Homo sapiens chromosome 7 genomic contig, alternate assembly & Up \\
\hline
\end{tabular}

niche microenvironments indeed, hence these niches might represent targets for treatments of cancer. Further understanding of the fate of cancer stem cells interfered by their particular microenvironment may bring out a new era for cancer treatment.

A cancer stem cell is thought to be quiescent and should be in G0/G1 phase [30]. Non-SP cells cultured with macrophage-like cells could be arrested on G1/S thus slow down the cell cycle. It therefore indicated that the microenvironment had an effect on cell-cycle-specific change. On the other hand, the migration of the non-SP cells is enhanced through conditioned culture. Therefore, these results implied that non-SP cells showed more aggressive characteristics with response to microenvironment.

Comprehensive analysis of gene expression using SSH revealed distinct differences between conditioned culture and non-conditioned culture cells. A few genes have been found to be evidently up-regulated in conditioned cultured non-SP cells. Genes such as ARMER, PCBP1 and PDHB were only expressed in conditioned cultured non-SP cells, which can be validated by Northern blotting analysis. ARMER is an apoptotic regulator in the 


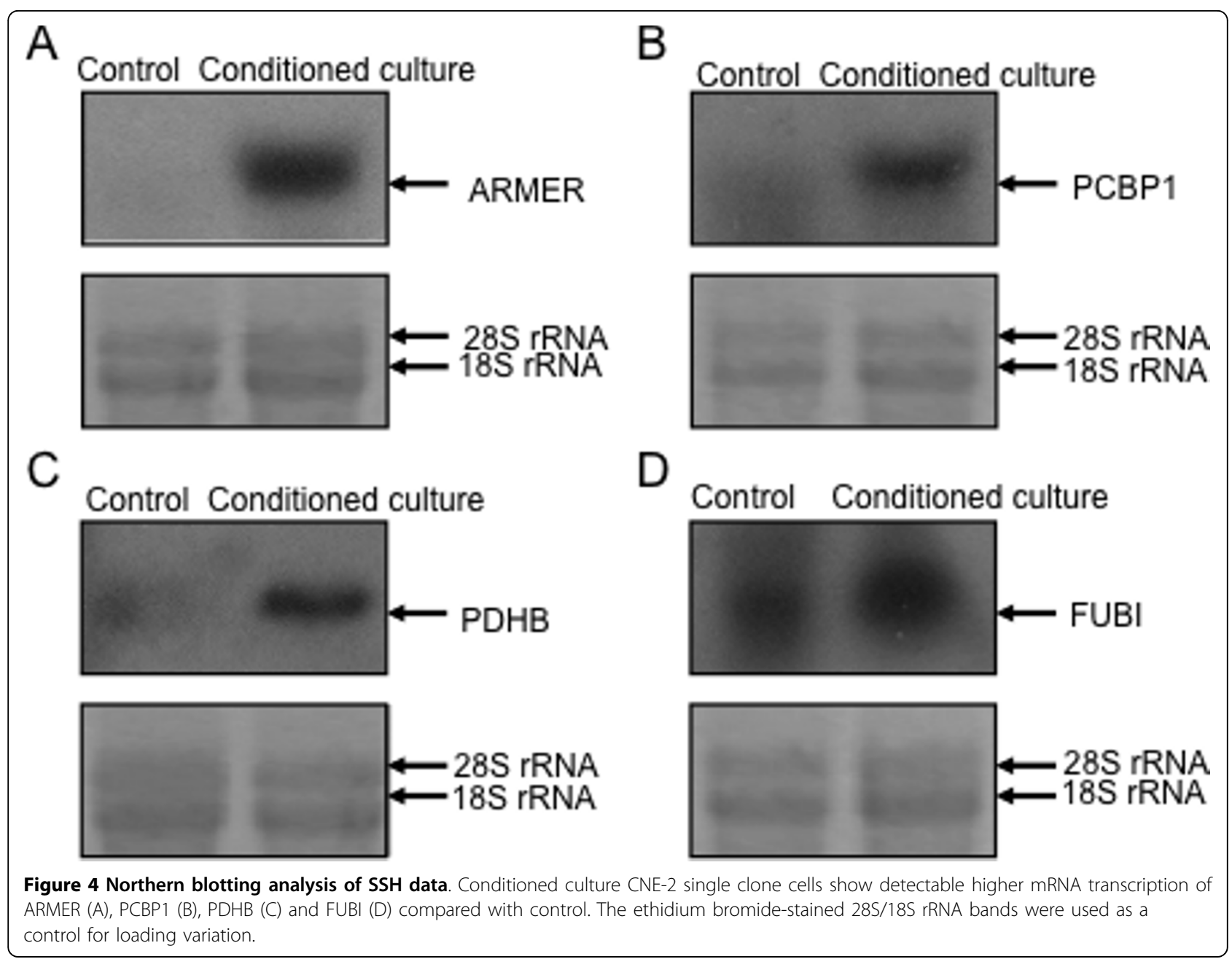

membrane of the endoplasmic reticulum [31], and was one of the most intensely up-regulated gene when cultured with the differentiated THP-1 conditioned media. Figure 3 reveals a large amount of apoptotic cells in the control and proportionally less in the conditioned culture population. Thus, the possible anti-apoptotic effect of ARMER may be induced when cultured with the conditioned medium. While PCBP1 plays a role in the protein-protein interaction network for human inherited ataxias and disorders of Purkinje cell degeneration [32]. PDHB is involved in tricarboxylic acid cycle of fibroblast [33]. We also found that FUBI mRNA transcript level was increased in conditioned cultured cells compared with control. Overexpression of FUBI leads to cell death, which can be halted by Bcl-2 or inhibition of caspases $[29,34]$. We have tried to compare our gene profile data with those of similar study on hepatocellular carcinoma, thyroid cancer and lung adenocarcinoma, but they are not in the same pattern suggesting the heterogenic nature of different malignancies. None of the up-regulated genes in non-SP cells found here have been documented to be involved in NPC. This might be partly explained by the different characteristics of nonSP cells and SP cells. The abundance of SP in CSCs from the same tumor contributes to distinct gene expression patterns, which has been often neglected by previous studies for many years.

\section{Conclusion}

We have identified, for the first time, non-SP single clone cells can generate SP phenotype when they are cultured with macrophage-like cells. It should be noted that non-SP single clone cells derived directly from NPC CNE-2 cells would like to maintain non-SP characters, whereas non-SP cells sorted with FACS were inclined to gain SP. The underneath mechanism of the interesting phenomena is far yet clear. Further studies are needed to further pin-point the original source of the cancer stem cell in NPC and apply it for establishment a novel therapy of this malignancy. 


\section{Acknowledgements}

This research work was supported by NSF 30772476 and 30873084 (to Q.L.) NSF 30700974 (to J. X. C) and Postdoctoral Foundation of China 20060400775 (to J. X. C). We thank Min Yan, Li-Hui Wang, Jie Xu, Yan Zhao, Jin-E Yao and other members in Liu Lab for technical assistance.

\section{Author details}

${ }^{1}$ State Key Laboratory of Oncology in South China, Cancer Center, Sun Yatsen University, 650 Dongfeng Road, Guangzhou 510060, PR China. ${ }^{2}$ The Jackson Laboratory, 600 Main Street, Bar Harbor, Maine 04609, USA. ${ }^{3}$ Department of Pathology, University of Cambridge, Hills Road, Cambridge BS2 0QQ, UK. ${ }^{4}$ Department of Hematology, Third Affiliated Hospital, Sun Yatsen University, 600 Tianhe Road, Guangzhou 510630, PR China. ${ }^{5}$ College of Life Sciences, Zhejiang University, 388 Yuhangtang Road, Hangzhou 310058, PR China. ${ }^{6}$ Department of Emergency, First Affiliated Hospital, Sun Yat-sen University, 58 Zhongshan 2nd Road, Guangzhou 510060, PR China.

\section{Authors' contributions}

JXC, YXZ and QL designed and performed the study and wrote the manuscript. YXC, ZJL, ZMD, JYL, YL and FMZ also performed the migration, flow cytometry, subtraction suppression hybridization and northern blotting experiments, as well as assisted in revising it critically for important intellectual content. All authors read and approved the final manuscript.

\section{Competing interests}

The authors declare that they have no competing interests.

\section{Received: 24 August 2009}

Accepted: 25 February 2010 Published: 25 February 2010

\section{References}

1. Sanai N, Alvarez-Buylla A, Berger MS: Neural stem cells and the origin of gliomas. N Engl J Med 2005, 353:811-822.

2. Reya T, Morrison SJ, Clarke MF: Weissman I.L., Stem cells, cancer, and cancer stem cells. Nature 2001, 414:105-111.

3. Pardal R, Clarke MF, Morrison SJ: Applying the principles of stem-cell biology to cancer. Nat Rev Cancer 2003, 3:895-902

4. Lapidot T, Sirard C, Vormoor J, Murdoch B, Hoang T, Caceres-Cortes J, Minden M, Paterson B, Caligiuri MA, Dick JE: A cell initiating human acute myeloid leukaemia after transplantation into SCID mice. Nature 1994, 367:645-648.

5. Bonnet D, Dick JE: Human acute myeloid leukemia is organized as a hierarchy that originates from a primitive hematopoietic cell. Nat Med 1997, 3:730-737.

6. Kim CF, Jackson EL, Woolfenden AE, Lawrence S, Babar I, Vogel S, Crowley D, Bronson RT, Jacks T: Identification of bronchioalveolar stem cells in normal lung and lung cancer. Cell 2005, 121:823-835.

7. Singh SK, Hawkins C, Clarke ID, Squire JA, Bayani J, Hide T, Henkelman RM Cusimano MD, Dirks PB: Identification of human brain tumour initiating cells. Nature 2004, 432:396-401.

8. Al-Hajj M, Wicha MS, Benito-Hernandez A, Morrison SJ, Clarke MF: Prospective identification of tumorigenic breast cancer cells. Proc Natl Acad Sci USA 2003, 100:3983-3988.

9. Woodward WA, Chen MS, Behbod F, Rosen JM: On mammary stem cells. $J$ Cell Sci 2005, 118:3585-3594.

10. Al-Hajj M, Clarke MF: Self-renewal and solid tumor stem cells. Oncogene 2004, 23:7274-7282.

11. Tokar EJ, Ancrile BB, Cunha GR, Webber MM: Stem/progenitor and intermediate cell types and the origin of human prostate cancer. Differentiation 2005, 73:463-473

12. Bissell MJ, Labarge MA: Context, tissue plasticity, and cancer: are tumor stem cells also regulated by the microenvironment?. Cancer Cell 2005, 7:17-23.

13. Calabrese C, Poppleton H, Kocak M, Hogg TL, Fuller C, Hamner B, Oh EY, Gaber MW, Finklestein D, Allen M, Frank A, Bayazitov IT, Zakharenko SS, Gajjar A, Davidoff A, Gilbertson RJ: A perivascular niche for brain tumor stem cells. Cancer Cell 2007, 11:69-82.
14. Gilbertson RJ, Rich JN: Making a tumour's bed: glioblastoma stem cells and the vascular niche. Nat Rev Cancer 2007, 7:733-736.

15. Wei WI, Sham JS: Nasopharyngeal carcinoma. Lancet 2005, 365:2041-2054.

16. Hajiioannou JK, Kyrmizakis DE, Datseris G, Lachanas V, Karatzanis AK, George Velegrakis AA: Nasopharyngeal-type undifferentiated carcinoma (lymphoepithelioma) of paranasal sinuses: Rare case and literature review. J Otolaryngol 2006, 35:147-151.

17. Jeyakumar A, Brickman TM, Jeyakumar A, Doerr T: Review of nasopharyngeal carcinoma. Ear Nose Throat J 2006, 85:168-170, 172-163, 184.

18. Zhou X, Cui J, Macias V, Kajdacsy-Balla AA, Ye H, Wang J, Rao PN: The progress on genetic analysis of nasopharyngeal carcinoma. Comp Funct Genomics 2007, 57513.

19. Zhang XY, Varthi M, Sykes SM, Phillips C, Warzecha C, Zhu W, Wyce A Thorne AW, Berger SL, McMahon SB: The putative cancer stem cell marker USP22 is a subunit of the human SAGA complex required for activated transcription and cell-cycle progression. Mol Cell 2008, 29:102-111.

20. Schatton T, Murphy GF, Frank NY, Yamaura K, Waaga-Gasser AM, Gasser M, Zhan Q, Jordan S, Duncan LM, Weishaupt C, Fuhlbrigge RC, Kupper TS, Sayegh MH, Frank MH: Identification of cells initiating human melanomas. Nature 2008, 451:345-349.

21. Mitsutake N, Iwao A, Nagai K, Namba H, Ohtsuru A, Saenko V, Yamashita S: Characterization of side population in thyroid cancer cell lines: cancer stem-like cells are enriched partly but not exclusively. Endocrinology 2007, 148:1797-1803.

22. Haraguchi N, Utsunomiya $T$, Inoue $H$, Tanaka F, Mimori K, Barnard GF Mori M: Characterization of a side population of cancer cells from human gastrointestinal system. Stem Cells 2006, 24:506-513.

23. Szotek PP, Pieretti-Vanmarcke R, Masiakos PT, Dinulescu DM, Connolly D, Foster R, Dombkowski D, Preffer F, Maclaughlin DT, Donahoe PK: Ovarian cancer side population defines cells with stem cell-like characteristics and Mullerian Inhibiting Substance responsiveness. Proc Natl Acad Sci USA 2006, 103:11154-11159.

24. Ho MM, Ng AV, Lam S, Hung JY: Side population in human lung cancer cell lines and tumors is enriched with stem-like cancer cells. Cancer Res 2007, 67:4827-4833.

25. Chiba T, Miyagi S, Saraya A, Aoki R, Seki A, Morita Y, Yonemitsu Y, Yokosuka O, Taniguchi H, Nakauchi H, Iwama A: The polycomb gene product BMI1 contributes to the maintenance of tumor-initiating side population cells in hepatocellular carcinoma. Cancer Res 2008, 68:7742-7749.

26. Shi GM, Xu Y, Fan J, Zhou J, Yang XR, Qiu SJ, Liao Y, Wu WZ, Ji Y, Ke AW Ding ZB, He YZ, Wu B, Yang GH, Qin WZ, Zhang W, Zhu J, Min ZH, Wu ZQ: Identification of side population cells in human hepatocellular carcinoma cell lines with stepwise metastatic potentials. J Cancer Res Clin Oncol 2008, 134:1155-1163.

27. Prince ME, Sivanandan R, Kaczorowski A, Wolf GT, Kaplan MJ, Dalerba P, Weissman IL, Clarke MF, Ailles LE: Identification of a subpopulation of cells with cancer stem cell properties in head and neck squamous cell carcinoma. Proc Natl Acad Sci USA 2007, 104:973-978.

28. Wang J, Guo LP, Chen LZ, Zeng YX, Lu SH: Identification of cancer stem cell-like side population cells in human nasopharyngeal carcinoma cell line. Cancer Res 2007, 67:3716-3724

29. Patrawala L, Calhoun T, Schneider-Broussard R, Zhou J, Claypool K, Tang DG: Side population is enriched in tumorigenic, stem-like cancer cells, whereas ABCG2+ and ABCG2- cancer cells are similarly tumorigenic. Cancer Res 2005, 65:6207-6219.

30. Dean M, Fojo T, Bates S: Tumour stem cells and drug resistance. Nat Rev Cancer 2005, 5:275-284

31. Lui HM, Chen J, Wang L, Naumovski L: ARMER, apoptotic regulator in the membrane of the endoplasmic reticulum, a novel inhibitor of apoptosis. Mol Cancer Res 2003, 1:508-518.

32. Lim J, Hao T, Shaw C, Patel AJ, Szabo G, Rual JF, Fisk CJ, Li N, Smolyar A, Hill DE, Barabási AL, Vidal M, Zoghbi HY: A protein-protein interaction network for human inherited ataxias and disorders of Purkinje cell degeneration. Cell 2006, 125:801-814. 
33. Huh TL, Casazza JP, Huh JW, Chi YT, Song BJ: Characterization of two CDNA clones for pyruvate dehydrogenase E1 beta subunit and its regulation in tricarboxylic acid cycle-deficient fibroblast. J Biol Chem 1990, 265:13320-13326.

34. Mourtada-Maarabouni M, Kirkham L, Farzaneh F, Williams GT: Regulation of apoptosis by fau revealed by functional expression cloning and antisense expression. Oncogene 2004, 23:9419-9426.

Pre-publication history

The pre-publication history for this paper can be accessed here:http://www. biomedcentral.com/1471-2407/10/68/prepub

doi:10.1186/1471-2407-10-68

Cite this article as: Cao et al:: Pluripotency-associated genes in human nasopharyngeal carcinoma CNE-2 cells are reactivated by a unique epigenetic sub-microenvironment. BMC Cancer 2010 10:68.

\section{Submit your next manuscript to BioMed Central} and take full advantage of:

- Convenient online submission

- Thorough peer review

- No space constraints or color figure charges

- Immediate publication on acceptance

- Inclusion in PubMed, CAS, Scopus and Google Scholar

- Research which is freely available for redistribution

Submit your manuscript at www.biomedcentral.com/submit 